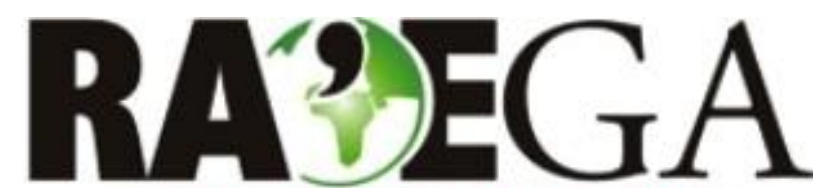

O ESPAÇO GEOGRÁFICO EM ANÁLISE

\title{
USO DA TERRA NO ASSENTAMENTO ANTÔNIO CONSELHEIRO NO ESTADO DE MATO GROSSO
}

\section{LAND USE IN ANTÔNIO CONSELHEIRO SETTLEMENT IN MATO GROSSO STATE}

\author{
Thaís Vasconcelos Silva ${ }^{1}$, Tadeu Miranda Queiroz ${ }^{2}$, Edinéia Santos Galvanin ${ }^{3}$
}

\section{RESUMO}

O uso da terra nos assentamentos rurais está voltado, principalmente, para atividades como criação de animais e desenvolvimento de culturas temporárias e permanentes para subsistência e geração de renda. $O$ objetivo deste trabalho é avaliar o uso da terra no Assentamento Antônio Conselheiro localizado na Microrregião de Tangará da Serra, estado de Mato Grosso. Foram utilizadas imagens dos satélites Landsat-5, do ano de 1995, e do Landsat-8, do ano de 2015, que foram processadas, classificadas e quantificadas no software Spring. O software ArcGis foi utilizado para elaboração do layout dos mapas das classes temáticas. O grau de antropização foi avaliado por meio do Índice de Transformação Antrópica. As classes mapeadas foram vegetação natural, pastagem, agricultura e massas d'água. Os resultados mostram que houve alteração em todas as classes de uso entre os anos de 1995 e 2015. A vegetação natural teve sua área reduzida, enquanto as classes pastagem, agricultura e massas d'água apresentaram aumento de área. A diminuição da classe vegetação natural pode estar relacionada com o aumento da pastagem e da agricultura, principalmente. $O$ aumento das massas d'água pode estar relacionado com a redução da vegetação natural presente nas margens dos cursos d'água. A alteração de classe do ITA, passando de regular em 1995 para degradado em 2015, evidencia que houve aumento no grau de antropização na área com a criação do Assentamento Antônio Conselheiro.

PALAVRAS-CHAVE: Geotecnologias. Uso e cobertura da terra. Transição Cerrado Amazônia. Assentamento de reforma agrária.

\section{ABSTRACT}

Land use in rural settlements is aimed mainly for activities such as breeding and temporary and permanent crops development for subsistence and income generation. The objective of this study was to evaluate the land use in Antônio Conselheiro Settlement located in the Tangará da Serra micro-region, State of Mato Grosso. The images of Landsat-5 satellite, of 1995, and Landsat-8, the 2015, were used, which were processed, classified and quantified in Spring software. The ArcGIS software was used to prepare the layout of the thematic classes maps. The antropization degree was assessed by the Anthropic Transformation Index. Mapped classes were natural vegetation, grazing, agriculture and water masses. The results show that there was a change in the use of all classes between 1995 and 2015. The natural vegetation area was reduced, while classes grazing, agriculture and water masses showed an area increase. The decrease of natural vegetation class can be related to the increase in pasture and agriculture, mainly. The increase in water masses can be related to the reduction of natural vegetation present on the banks of waterways. The change in the Anthropic Transformation Index class, from regular in 1995 to run down in 2015, shows that there was an increase in the degree of human disturbance in the area with the creation of the Antônio Conselheiro Settlement.

KEY-WORDS: Geotechnologies. Land use and cover. Amazon Cerrado Transition. Agrarian reform Settlement

Recebido em: 14/12/2015

Aceito em: 04/07/2017

\footnotetext{
${ }^{1}$ Universidade do Estado de Mato Grossol,Barra do Bugres/MT e-mail: thais.silva@jna.ifmt.edu.br

2 Universidade do Estado de Mato Grossol,Barra do Bugres/MT, e-mail: tdmqueiroz@yahoo.com.br

3 Universidade do Estado de Mato Grossol,Barra do Bugres/MT e-mail: galvanin@gmail.com
} 


\section{USO DA TERRA NO ASSENTAMENTO ANTÔNIO CONSELHEIRO NO ESTADO DE MATO GROSSO}

\section{INTRODUÇÃO}

O uso da terra é definido em função das atividades desenvolvidas em determinada área que, no caso de propriedades rurais, são voltadas principalmente para o estabelecimento de culturas e criação de animais, além de moradia e recreação. Estima-se que as mudanças nos usos da terra sejam responsáveis por $75 \%$ das emissões de gases de efeito-estufa no Brasil, com especial destaque para as queimadas e o desmatamento no Cerrado e na Floresta Amazônica (BERMANN, 2008), fatores esses associados à antropização.

O estado de Mato Grosso é considerado uma das últimas fronteiras de expansão agrícola e de redistribuição espacial da população do país. Entretanto, as transformações na estrutura produtiva nas últimas décadas provocaram o aumento da concentração fundiária. Neste sentido, os assentamentos de reforma agrária representam uma alternativa concreta para reverter este processo (CUNHA, 2006).

A implantação de assentamentos de reforma agrária promove a diversificação da produção e, consequentemente, a oferta de maior variedade de produtos no mercado local, principalmente de produtos agropecuários, sobretudo em regiões onde há o predomínio de monoculturas cultivadas em grande escala como, soja, milho e cana-de-açúcar (LEITE et al., 2004).

As geotecnologias que vêm sendo utilizadas para estudos de uso da terra há algum tempo e têm se mostrado satisfatórias (FIDALGO et al., 2003; CASTELANI; BATISTA, 2007; CORSEUIL et al., 2009; CASTELANI et al., 2012; COUTINHO, 2015), inclusive em áreas onde foram criados assentamentos de reforma agrária (FERNANDES, 2008; QUEIROZ JUNIOR et al., 2012).

Inserido na região de transição entre os biomas Cerrado e Amazônia, o Assentamento Antônio Conselheiro (AAC) localiza-se na
Microrregião de Tangará da Serra (IBGE, 1990), no estado de Mato Grosso, abrangendo parte dos municípios de Tangará da Serra, Barra do Bugres e Nova Olímpia. Criado para regularizar a situação dos posseiros que ocupavam a Gleba Tapirapuã em 1996, mais de 39.000 hectares foram divididos em 999 unidades agrícolas familiares, conforme Portaria Incra no 109, de 12 de dezembro de 1997 (BRASIL, 1997).

A divisão da unidade produtiva para constituição de assentamento de reforma agrária pode resultar em alterações nos usos da terra que podem ser avaliadas pelo cálculo do Índice de Transformação Antrópica (ITA). As alterações decorrentes das mudanças nos usos da terra podem causar impactos aos diversos compartimentos ambientais, como a água, por exemplo.

A água utilizada pela população é proveniente dos mananciais superficiais e subterrâneos existentes na área do $\mathrm{AAC}$ e, muitas vezes, não é tratada ou se quer filtrada. Além disso, a água é essencial para o desenvolvimento de culturas agrícolas e para a criação de animais que são as principais fontes de renda dos assentados.

Ademais, o rio Sepotuba juntamente com o rio Cabaçal destacam-se pela formação do rio Paraguai, que contribui para a maior planície inundável do planeta, o Pantanal.

Assim, objetivo deste trabalho é avaliar o uso da terra no Assentamento Antônio Conselheiro, estado de Mato Grosso.

\section{MATERIAL E MÉTODOS ÁREA DE ESTUDO}

$O$ estudo foi realizado no Assentamento Antônio Conselheiro (AAC), cuja área total é de 39.202,02 hectares, localizado entre as coordenadas geográficas $14^{\circ} 37^{\prime} 56^{\prime \prime}$ e $14^{\circ} 59^{\prime} 10^{\prime \prime} \mathrm{S}$ de latitude e $57^{\circ} 37^{\prime} 53^{\prime \prime}$ a $57^{\circ} 50^{\prime} 11^{\prime \prime} W$ de longitude (Figura 1). 


\section{USO DA TERRA NO ASSENTAMENTO ANTÔNIO CONSELHEIRO NO ESTADO DE MATO GROSSO}
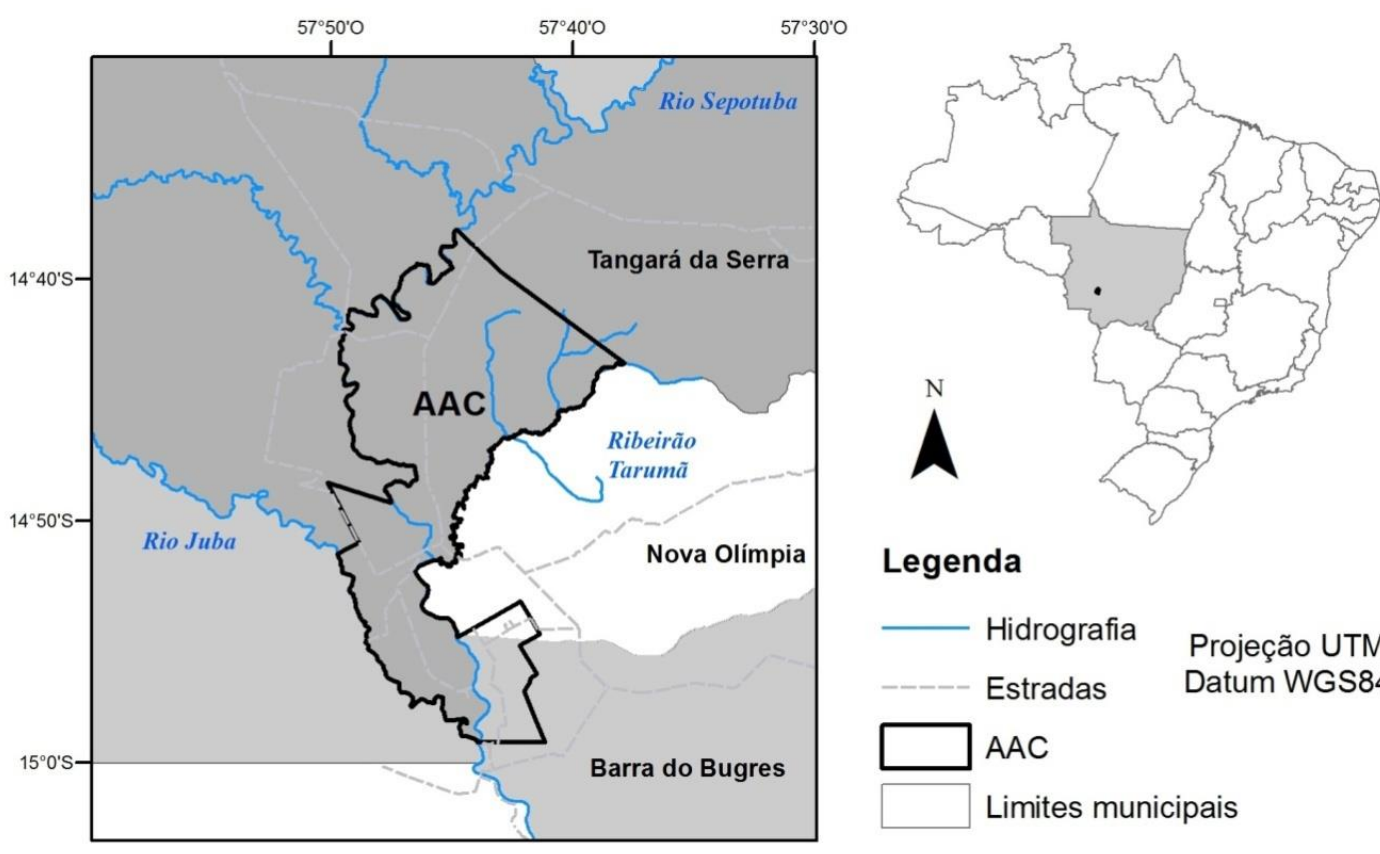

Legenda

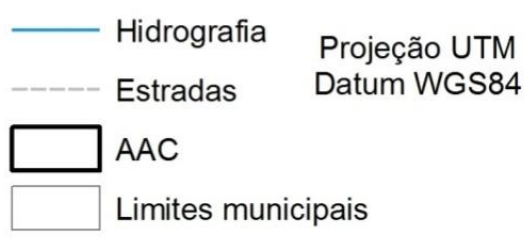

Figura 01 - Localização do Assentamento Antônio Conselheiro, estado de Mato Grosso.

O clima da região é caracterizado por dois períodos bem definidos, chuvoso no verão e seco no inverno, com altas temperaturas, denominado como Tropical Úmido Megatérmico (Awa) segundo a classificação de Köppen. De acordo com Dallacort et al. (2010), a região de Tangará da Serra apresenta temperatura média anual de $24{ }^{\circ} \mathrm{C}$, precipitação de $1500 \mathrm{~mm}$ e umidade relativa do ar de 70 a $80 \%$.

A área do AAC está inserida na bacia do rio Sepotuba compreendida no Bioma Amazônia e apresenta a fitofisionomia de Floresta Estacional Semidecidual (IBGE, 2004a) que se encontra em região de transição entre os biomas Cerrado e Amazônia onde é possível observar a existência de áreas de Savana (IBGE, 2004b).

Os solos da região são compostos por Latossolos Amarelos Distróficos, Neossolos Quartzarênicos Órticos e Flúvicos Distróficos, Argissolos Vermelhos Eutróficos e VermelhosAmarelos Distróficos e Cambissolos Háplicos Distróficos (IBGE, 2011).

\section{PROCEDIMENTOS METODOLÓGICOS}

Foi utilizada a imagem do satélite Landsat, órbita/ponto 228/070, do sensor Thematic Mapper (TM) datada do dia 29 de julho de 1995, disponibilizada no Catálogo de Imagens do Instituto Nacional de Pesquisas Espaciais (INPE) (BRASIL, 2015) com resolução espacial de 30 metros e radiométrica de 8 bits. A imagem Landsat 8, sensor Operational Land Imager (OLI), de 2015 foi obtida no dia 20 de julho e disponibilizada georreferenciada gratuitamente pelo United States Geological Service (USGS, 2015), cuja resolução espacial é de 30 metros e radiométrica de 16 bits.

No sistema Spring foi criado um banco de dados para processamento das imagens no sistema de coordenadas UTM, datum WGS84, zona 21S. A imagem de 1995 foi registrada com o auxílio da imagem Geocover, disponibilizada pelo USGS (USGS, 2015). As imagens foram recortadas com o auxílio do shape da área. A segmentação por crescimento de regiões foi realizada com limiar 8 de similaridade e 16 de área. Esta técnica visa agrupar pixels que possuem características espectrais semelhantes (CAMARA et al., 2013) e foi utilizada neste trabalho para delimitar as amostras utilizadas no treinamento e quantificação das classes de uso da terra (XAUD; EPIPHANIO, 2014). Os limiares 8 e 16 (similaridade e área) foram tomados como base em estudos realizados na Amazônia 


\section{USO DA TERRA NO ASSENTAMENTO ANTÔNIO CONSELHEIRO NO ESTADO DE MATO GROSSO}

(SHIMABUKURO et al., 1999; MARTINS JUNIOR et al., 2008).

A partir das definições do Manual de uso da Terra (IBGE, 2013), das observações em campo e das imagens de satélite foram definidas quatro classes, quais sejam: vegetação natural (florestal ou campestre, primárias e secundárias), pastagem (plantadas ou naturais), agricultura (culturas permanentes e temporárias diversificadas) e massas d'água (rios, córregos e reservatórios).

A classificação supervisionada da imagem foi realizada por meio de treinamento, que consiste na identificação de amostras de classes pelo usuário e avaliada pelo algoritmo Bhattacharya com aceitação de 99,9\%. A avaliação da exatidão do processo de classificação foi realizada por meio do índice Kappa (COHEN, 1960).

A validação da classificação de 1995 foi feita com o auxílio de mapas e informações obtidas junto aos assentados que conheceram a propriedade antes da estruturação do assentamento. De outubro de 2014 a junho de 2015 foram feitas visitas mensais ao assentamento durante as quais se procedeu a coleta de Pontos de Controle Terrestre (PCTs), com o auxílio de GPS e câmera fotográfica, para validar a classificação do ano de 2015.

Após o processamento as imagens foram exportadas para edição das classificações no software ArcMap, versão 10.1.

O Índice de Transformação Antrópica (ITA) foi calculado por meio da Equação 1.

ITA $=\frac{\sum(\% \text { uso } \times \text { peso })}{100}$ onde:

uso - área em porcentagem da classe de uso; peso - peso atribuído aos diferentes tipos de uso em relação ao grau de alteração antrópica.

O peso varia de 1 a 10 , sendo que 1 indica baixo grau de antropização e 10 indica as maiores pressões. Para que a atribuição de pesos seja mais adequada utiliza-se a divisão em quartis nos quais áreas pouco degradadas estão entre 0 e 2,5, regular de 2,5 a 5, degradado de 5 a 7,5 e muito degradado de 7,5 a 10 (CRUZ et al., 1998). A definição do peso atribuído às classes foi feito por meio de consulta sistemática denominada método Delphi a especialistas e pesquisadores que conhecem a área de estudo (SCHWENK; CRUZ, 2008).

\section{RESULTADOS E DISCUSSÃO}

O uso da terra na área de estudo sofreu alterações no período avaliado, conforme representado na Figura 2, e o aumento do grau de antropização foi verificado por meio da alteração de classe do ITA (Tabela 1). 

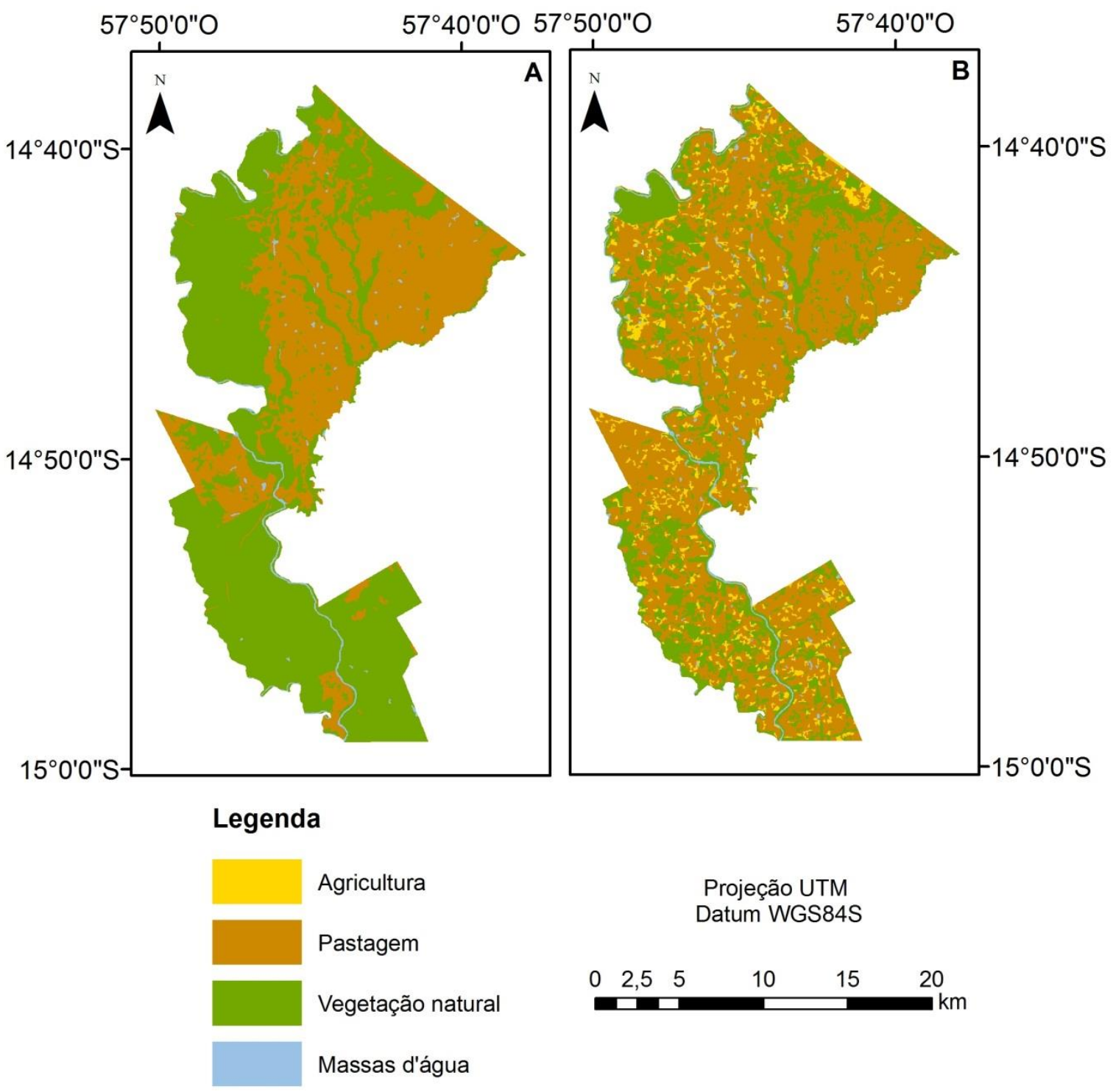

Figura 02 - Classes de uso da terra no AAC, estado de Mato Grosso, Brasil, nos anos de 1995 (A) e 2015

(B).

Os pesos atribuídos às classes de uso da terra e o Índice de Transformação Antrópica calculados para os anos de 1995 e 2015 estão relacionados na Tabela 1. 
Tabela 01 - Resultado do ITA nos anos de 1995 e 2015 na área do AAC.

\begin{tabular}{l|r|r|r|r|r}
\hline \multirow{2}{*}{ Classes } & \multicolumn{2}{|c|}{ Área(\%) } & \multirow{2}{*}{ Peso } & \multicolumn{2}{c}{ ITA } \\
\cline { 2 - 3 } & \multicolumn{1}{|c|}{$\mathbf{1 9 9 5}$} & $\mathbf{2 0 1 5}$ & & $\mathbf{1 9 9 5}$ & \multicolumn{1}{c}{$\mathbf{2 0 1 5}$} \\
\hline Vegetação natural & 59,58 & 27,62 & 1,0 & 0,60 & 0,28 \\
Pastagem & 38,97 & 63,24 & 8,0 & 3,12 & 5,06 \\
Agricultura & 0,00 & 7,02 & 6,0 & 0,00 & 0,42 \\
Massas d'água & 1,45 & 2,13 & 1,5 & 0,02 & 0,03 \\
\hline \multicolumn{1}{c|}{ Total } & $\mathbf{1 0 0}$ & $\mathbf{1 0 0}$ & & $\mathbf{3 , 7 4}$ & $\mathbf{5 , 7 9}$ \\
\hline
\end{tabular}

A acurácia do mapa gerado apresentado meio do estimador de acerto Kappa (Tabela 2).

na Figura 2 foi verificada pela matriz de erros, por

Tabela 02 - Resultado pelo estimulador de acerto Kappa.

\begin{tabular}{lll}
\hline & $\mathbf{1 9 9 5}$ & $\mathbf{2 0 1 5}$ \\
\hline Acurácia global (\%) & 99,90 & 99,65 \\
Índice Kappa & 0,99 & 0,99 \\
\hline
\end{tabular}

Os valores do índice Kappa de 0,8 são considerados excelentes por Landis e Koch (1977), Congalton e Green (1999) e Manel et al. (2001) e indicam que o resultado esperado para a classificação foi alcançado.

No ano de 1995, apenas a classe pastagem apresentou confusão espectral, sendo que $0,10 \%$ dos pixels foram erroneamente atribuídos à classe de vegetação natural. Esta confusão espectral pode estar associada à característica da pastagem local de possuir arbustos, que podem ser confundidos com a área de vegetação natural.

Em 2015, a maior confusão espectral ocorreu entre agricultura e pastagem $(0,27 \%)$ enquanto a menor ocorreu entre água $\mathrm{e}$ pastagem (0,02\%). A confusão entre agricultura e pastagem, em 2015, pode ter ocorrido em função da limpeza da área para o cultivo, o que pode ser espectralmente semelhante a pastagem na seca quando o solo fica mais exposto. Pastagem e agricultura tiveram o mesmo percentual de confusão espectral (0,03\%) em relação a vegetação natural em 2015. A vegetação natural da região tem por característica a perda de folhas no período de seca (vegetação caducifólia), o que pode ocasionar confusão espectral com agricultura, cultivo em solo exposto, pastagem e solo exposto na seca. As confusões espectrais verificadas na imagem do ano de 2015 podem ter ocorrido em virtude da grande transformação da área com a criação do AAC.

As alterações no uso da terra na área do AAC no período avaliado podem ser percebidas pela mudança de classe do ITA de regular, em 1995, para degradado, em 2015. A redução da área de vegetação nativa está relacionada com o aumento das áreas de pastagem, agricultura e massas d'água. Entretanto, a classe pastagem foi a que mais colaborou para o aumento do ITA. Nascimento et al. (2015) obtiveram resultados semelhantes no estudo da Bacia Hidrográfica do rio do Sangue na qual a área de vegetação natural cedeu espaço para agricultura e pastagem.

$\mathrm{Na}$ avaliação do uso da terra na Bacia do Córrego do Bezerro Vermelho Gouveia et al. (2013) evidenciaram no período de 27 anos que de acordo com o ITA o nível de antropização da área passou de regular para degradado em decorrência de mudanças na paisagem como o aumento da agricultura, a redução de cobertura florestal, eliminação da vegetação secundária e o aumento da lâmina d'água.

No AAC, a área de vegetação natural reduziu 31,96\% do ano de 1995 para 2015 enquanto a área pastagem aumentou em $21,27 \%$. Em estudo na bacia do rio Sepotuba realizado por Serigatto (2006) verificou-se que o uso da terra seguiu o mesmo padrão de ocupação 


\section{USO DA TERRA NO ASSENTAMENTO ANTÔNIO CONSELHEIRO NO ESTADO DE MATO GROSSO}

observado na área da Amazônia Legal, onde áreas de vegetação natural são convertidas em agricultura ou pastagem. O estudo da transformação antrópica na Bacia do rio Diamantino, no estado de Mato Grosso, identificou resultado semelhante com o aumento do grau de antropização associado, principalmente, à expansão de pastagem sobre áreas de vegetação natural, o que alterou a classificação de pouco degradada em 1993 e 2003 para regular em 2013 (COCCO et al., 2014).

A redução da área de vegetação natural em conjunto com o aumento da área de pastagem pode estar associada à formação de áreas de pastejo para criação de gado. Esta tendência ocorre na área de expansão da fronteira agrícola do estado de Mato Grosso, conforme evidenciado por estudos (MARGULIS, 2003; BABY et al., 2013). Lemos e Silva (2011) destacam que o rebanho bovino do estado de Mato Grosso está em ritmo de crescimento de 7,5\% ao ano, passando de 9 milhões de cabeças para cerca de 27 milhões entre os anos de 1990 e 2005.

As condições naturais de fragilidade do meio, relacionadas a aspectos hidrogeológicos, pedológicos e/ou climáticos, podem ser potencializadas pelas pressões decorrentes das ações do homem (CARVALHO, 2012). Estudos realizados por Vanzela et al. (2010), Salemi et al. (2012) e Rodrigues et al. (2015) encontraram evidências de alteração da dinâmica hidrológica de cursos d'água em diferentes localidades em decorrência de mudança dos usos da terra.

Outro aspecto importante a se destacar é que a implantação de um assentamento rural requer obras de infraestrutura como abertura de estradas, construção de pontes, escolas, pontos de comércio, entre outros. Ademais, após a divisão dos lotes entre os assentados é natural que o proprietário faça o isolamento de sua propriedade. Todas estas atividades demandam o uso de madeira que, no momento da criação do $A A C$, se encontrava à disposição na área de floresta, principalmente.

Portanto, uma vez que o trabalhador encontra-se de posse de sua área, o mesmo define os usos que serão dados àquela área. Assim, as escolhas da gestão ambiental do lote estão relacionadas aos interesses do agricultor $\mathrm{e}$ dependem de questões como mercado agrícola, acesso a financiamentos e legislação vigente, principalmente, a ambiental. Streck e Essi (2013) verificaram, nos assentamentos Potreiro Bonito e Terra Nova no município de Palmeira das Missões, estado do Rio Grande do Sul, que as dificuldades encontradas para a geração de renda nestas localidades contribuem para o desmatamento, uma vez que prioriza-se a sobrevivência da família em relação à preservação ambiental.

Antes da implantação do AAC, não havia área ocupada por agricultura na Gleba Tapirapuã uma vez que esta se destinava exclusivamente a criação extensiva de gado. Com a divisão da área em lotes para os assentados pode-se observar o início do cultivo agrícola, com destaque para banana, mandioca, citrus e milho. Assim, em 2015 a área de agricultura passou a ocupar 7,02\% incluindo cultivos diversificados em pequena escala para o consumo próprio e venda no comércio local. O aumento da diversificação de produtos no mercado local e regional é característica marcante da agricultura familiar que proporciona maior equilíbrio na economia regional (FRANÇA et al., 2009).

A área de massas d'água aumentou em 0,63\% de 1995 para 2015. Este aumento pode estar relacionado ao desmatamento no entorno dos corpos hídricos, fato este que deixa a superfície mais visível nas imagens utilizadas, o que demanda estudos mais detalhados.

As atividades antrópicas desenvolvidas na área do AAC continuarão a existir o que demonstra a importância do estudo do uso da terra. A acentuação do grau de antropização indica a necessidade de orientação das atividades desenvolvidas no sentido de minimizar as consequências principalmente pelo fato do $A A C$ estar inserido na área de contribuição da bacia do rio Paraguai que banha o Pantanal Matogrossense, maior planície de inundação contínua do planeta.

\section{CONCLUSÃO}

A avaliação dos usos da terra indica que as áreas de vegetação natural deram espaço, principalmente, a áreas de pastagem e agricultura, em função da constituição do AAC;

A alteração de classe do ITA de regular para degradado demonstra o aumento do grau de antropização na área do AAC entre os anos de 1995 e 2015; 


\section{USO DA TERRA NO ASSENTAMENTO ANTÔNIO CONSELHEIRO NO ESTADO DE MATO GROSSO}

O grau de antropização aumentou ao longo do tempo, o que pode trazer consequências negativas para a área do $A A C$ e seu entorno. Desta forma, estudos como de qualidade da água podem contribuir para melhor compreensão das implicações do uso da terra no AAC e região.

\section{REFERÊNCIAS BIBLIOGRÁFICAS}

BABY, A. L. T.; BUSCHBACHER, R.; ROSSETE, A. N. Estudo da dinâmica de desmatamento do município de Cotriguaçu - Mato Grosso, Brasil. In: XVI Simpósio Brasileiro de Sensoriamento Remoto - SBSR, 2013, Foz do Iguaçu - PR. Anais... Foz do Iguaçu -PR: INPE, abr. 2013. p. 7079-7085.

BERMANN, C. Crise ambiental e as energias renováveis. Ciência e Cultura, São Paulo, v. 60, n. 3, p. 20-29, set. 2008.

BRASIL. Instituto Nacional de Colonização e Reforma Agrária - INCRA. Portaria INCRA/SR(13) no 109, de 12 de dezembro de 1997. Dispõe sobre a destinação de imóvel para fins de Reforma Agrária e dá outras providências. Diário Oficial [da] República Federativa do Brasil, Brasília, DF, 15 dez. 1997. Seção 1, p. 27.

Ministério da Agricultura, Pecuária e Abastecimento. Instituto Nacional de Pesquisas Espaciais. Catálogo de Imagens. São José dos Campos - SP. 2015. Disponível em: <http://www.dgi.inpe.br/CDSR/>. Acesso em:13 jun. 2015.

CAMARA, G.; VALERIANO, D.; VIANEI, J. Metodologia para o cálculo da taxa anual de desmatamento na Amazônia Legal. Revisado por Luis Maurano. Coordenadoria Geral de Observação da Terra. Programa Amazônia. Instituto Nacional de Pesquisas Espaciais (INPE). São José dos Campos, 37 p. 2013.

CARVALHO, M. E. S. Vulnerabilidade hídrica na bacia sergipana do rio Vaza Barris. RA'EGA, Curitiba, v. 25, p. 186-217, 2012.

CASTELANI, C. S.; BATISTA, G. T. Mapeamento de Áreas de Preservação Permanente (APP) do município de Santo Antônio do Pinhal, SP: um subsídio à preservação ambiental. Revista Ambiente \& Água, Taubaté, v. 2, n. 1, p. 30-43, 2007.

CASTELANI, C. S.; BATISTA, G. T.; TARGA, M. S.; DIAS, N. W. Determinação de áreas prioritárias para o restabelecimento da cobertura florestal, apoiada no uso de geotecnologias. Revista Ambiente \& Água, Taubaté, v. 7, n. 3, p. 113-126, 2012.

COCCO, J.; RIBEIRO, H. V.; GALVANIN, E. A. S. Análise da transformação antrópica na Bacia Hidrográfica do Rio Diamantino. In: 5o Simpósio de Geotecnologias no Pantanal, 2014, Campo Grande - MS. Anais... Campo Grande - MS: Embrapa Informática Agropecuária/INPE, 2014. p. 26-36.

COHEN, J. A coefficient of agreement for nominal scales. Educational and Psychological Measurement, Santa Barbara - Califórnia, v. 20, n. 1, p. 37-46, 1960.

CONGALTON, R. G.; GREEN, K. Assessing the accuracy of remotely sensed data: principles and practices. New York: Lewis Publisers, 1999. 136p.

CORSEUIL, C. W.; CAMPOS, S.; RIBEIRO, F. L.; PISSARRA, T. C. T.; RODRIGUES, F. M. Geoprocessamento e sensoriamento remoto aplicado na determinação da aptidão agrícola de uma microbacia. Irriga, Botucatu, v. 14, n. 1, p. 12-22, jan./mar. 2009.

COUTINHO, L. M. Mapeamento de uso do solo em Área de Preservação Permanente (APP) na bacia do Córrego Itabira, Cachoeiro de Itapemirim - ES. In: XVII Simpósio Brasileiro de Sensoriamento Remoto, 2015, João Pessoa - PB. Anais... João Pessoa - PB: INPE, 2015. p. 35-42.

CRUZ, C. B. M.; TEIXEIRA, A. J. A.; BARROS, R. S.; ARGENTO, M. S. F.; MAYR, L. M.; MENEZES, P. M. L. Carga antrópica da bacia hidrográfica da baía de Guanabara. In: IX Simpósio Brasileiro de Sensoriamento Remoto, 1998, Santos - SP. Anais... Santos - SP: INPE, 1998. p. 99-109.

CUNHA, J. M. P. Dinâmica migratória e o processo de ocupação do Centro-Oeste brasileiro: o caso de Mato Grosso. Revista Brasileira de Estudos de População, São Paulo, v. 23, n. 1, p. 87-107, jan./jun. 2006.

DALLACORT, R.; MOREIRA, P. S. P.; INOUE, M. H.; SILVA, D. J.; CARVALHO, I. F.; SANTOS, C. Wind speed and direction characterization in Tangará da Serra, Mato Grosso State, Brazil. Revista Brasileira de Meteorologia, São José dos Campos - SP, v. 25, n. 3, p.359-364, 2010.

FERNANDES, L. C. Estudo multi-temporal do uso, ocupação e perda de solos em projetos de assentamentos em Rondônia. 2008. $133 \mathrm{f}$. Dissertação (Mestrado em Geociências e Meio 
Ambiente) - Universidade Estadual Paulista UNESP, Rio Claro, 2008.

FIDALGO, E. C. C; CREPANI, E.; DUARTE, V.; SHIMABUKURO, Y. E.; PINTO, R. M. S.; DOUSSEAU, S. L. Mapeamento do uso e da cobertura atual da terra para indicação de áreas disponíveis para reservas legais: estudo em nove municípios da região Amazônica. Revista Árvore, Viçosa, v. 27, n. 6, p. 871-877, 2003.

FRANÇA, C. G.; DEL GROSSI, M. E.; MARQUES, V. P. M. A. O censo agropecuário 2006 e a agricultura familiar no Brasil. Ministério do Desenvolvimento Agrário. NEAD Debate 18. Brasília: MDA, 2009. 96p.

GOUVEIA, R. G. L.; GALVANIN, E. A. S.; NEVES, S. M. A. S. Aplicação do Índice de Transformação Antrópica na análise multitemporal da bacia do córrego do Bezerro Vermelho em Tangará da Serra - MT. Revista Árvore, Viçosa, v. 37, n. 6, p. 1045-1054, 2013.

IBGE. Instituto Brasileiro de Geografia e Estatística. Divisão regional do Brasil em mesorregiões e microrregiões geográficas. Rio de Janeiro: 1990, v. 1, 153 p.

Instituto Brasileiro de Geografia e Estatística. Embrapa. Mapa de solos do Brasil. Rio de Janeiro: IBGE, 2011. Escala 1:5.000.000.

Instituto Brasileiro de Geografia e Estatística. Manual Técnico de Uso da Terra. Rio de Janeiro: IBGE,3. ed., 2013. 171p., il. (Manuais Técnicos em Geociências, n.7)

Instituto Brasileiro de Geografia e Estatística. Mapa de Biomas do Brasil: primeira aproximação. Rio de Janeiro: IBGE, 2004a. Escala 1:5.000.000.

Instituto Brasileiro de Geografia e Estatística. Mapa de Vegetação do Brasil. Rio de Janeiro: IBGE, 2004b. Escala 1:5.000.000.

LANDIS, J. R.; KOCH, G. G. The measurement of observer agreement for categorical data. Biometrics, Washington DC, v. 33, p. 159-174, mar. 1977.

LEITE, S.; HEREDIA, B.; MEDEIROS, L.; PALMEIRA, M.; CINTRÃO, R. Impactos dos assentamentos: um estudo sobre o meio rural brasileiro. Brasília: Núcleo de Estudos Agrários e Desenvolvimento Rural - NEAD, 1. ed. 2004. 392 p.

LEMOS, A. L. F.; SILVA, J. A. Desmatamento na Amazônia Legal: evolução, causas, monitoramento e possibilidades de mitigação através do Fundo Amazônia. Floresta e Ambiente, Seropédica - RJ, v. 18, n. 1, p. 98-108, jan./mar. 2011.

MANEL, S.; WILLIAMS, H. C.; ORMEROD, S. J. Evaluating presence-absence models in ecology: the need to account for prevalence. Journal of Applied Ecology, Londres - UK, v. 38, p. 921-931, 2001.

MARGULIS, S. Causas do desmatamento da Amazônia Brasileira. Banco Mundial, Brasília, 100 p., jun. 2003.

MARTINS JUNIOR, A. F.; WAICHMAN, A. V.; VILLAMIZAR, E. A. R. Classificação e estimativa das áreas alagáveis da bacia do rio Purus, Amazônia Ocidental, Brasil. In: Simpósio Brasileiro de Ciências Geodésicas e Tecnologias da Geoinformação, 2008, Recife - PE. Anais... Referência 207. Recife - PE, 2008.

NASCIMENTO, D. L.; GALVANIN, E. A. S.; RIBEIRO, H. V.; COCCO, J. Análise e previsões das ações antrópicas para a bacia do rio do Sangue - Mato Grosso/Brasil. Revista de Estudos Sociais, n. 34, v. 17, p. 52-63, 2015.

RODRIGUES, E. L.; ELMIRO, M. A. T.; BRAGA, F. A.; JACOBI, C. M.; ROSSI, R. D. Impact of changes in land use in the flow of the Pará River Basin, MG. Revista Brasileira de Engenharia Agrícola e Ambiental, v. 19, n. 1, p. 70-76, 2015.

QUEIROZ JÚNIOR, V. S.; OLIVEIRA, R. M.; CARVALHO, L. S.; BENINCÁ, M. C. Geotecnologias aplicadas ao levantamento de uso do solo em assentamento de reforma agrária, Sudoeste de Goiás. In: XXI Encontro Nacional de Geografia Agrária, 2012, Uberlândia, Anais... Uberlândia: UFU, 2012. p. 1-11.

SALEMI, L. F.; GROPPO, J. D.; TREVISAN, R.; SEGHESI, G. B.; MORAES, J. M.; FERRAZ, S. F. B.; MARTINELLI, L. A. Consequências hidrológicas da mudança de uso da terra de floresta para pastagem na região da floresta tropical pluvial atlântica. Revista Ambiente \& Água, Taubaté, v. 7, n. 3, p. 127-140, 2012.

SCHWENK, L. M.; CRUZ, C. B. M. Conflitos socioeconômicos-ambientais relativos ao avanço do cultivo da soja em áreas de influência dos eixos de integração e desenvolvimento no Estado de Mato Grosso. Acta Scientiarium Agronomy, Maringá - PR, v. 30, n. 4, p. 501-511, 2008. 


\section{USO DA TERRA NO ASSENTAMENTO ANTÔNIO CONSELHEIRO NO ESTADO DE MATO GROSSO}

SERIGATO, E. M. Delimitação automática das Áreas de Preservação Permanente e identificação dos conflitos de uso da terra na bacia hidrográfica do rio Sepotuba - MT. 2006. 188f. Tese (Doutorado em Ciência Florestal), Universidade Federal de Viçosa, Viçosa, MG, 2006.

SHIMABUKURO, Y. E.; DUARTE, V.; SANTOS, J. R.; MELLO, E. M. K.; MOREIRA, J. C. Levantamento de áreas desflorestadas na Amazônia através de processamento digital de imagens orbitais. Floresta e Ambiente, Seropédica - RJ, v. 6, n. 1, p. 38-44, jan./dez. 1999.

STRECK, M. T.; ESSI, L. Áreas de preservação permanente e reserva legal: experiência e educação ambiental envolvendo famílias de produtores rurais. Revista do Centro de Ciências Naturais e Exatas, Santa Maria - RS, v. 14, n. 14, p. 2832-2838, 2013.
USGS. United States Geological Survey. Earth Explorer. 2015.2 Disponível em: <http://www.usgs.gov/>. Acesso em: 22 jul. 2015.

VANZELA, L. S.; HERNANDEZ, F. B. T.; FRANCO, R. A. M. Influência do uso e ocupação do solo nos recursos hídricos do Córrego Três Barras, Marinópolis. Revista Brasileira de Engenharia Agrícola e Ambiental, Campina Grande - PB, v. 14, n. 1, p. 55-64, 2010.

XAUD, M. R.; EPIPHANIO, J. C. N. Dinâmica do uso e cobertura da terra no sudeste de Roraima utilizando técnicas de deteç̧ão de mudanças. Acta Amazonica, Manaus - AM, v. 44, n. 1, p. 107120,2014 